\title{
Vector Genomes per Dose
}

National Cancer Institute

\section{Source}

National Cancer Institute. Vector Genomes per Dose. NCI Thesaurus. Code C124471.

A unit for cloning vector amounts expressed as the number of vector genomes per dose. 